\title{
Article \\ A Comparative Metabolomic Analysis Reveals the Nutritional and Therapeutic Potential of Grains of the Traditional Rice Variety Mappillai Samba
}

\author{
Veera Ranjani Rajagopalan (D), Sudha Manickam and Raveendran Muthurajan *(D)
}

check for

updates

Citation: Rajagopalan, V.R.;

Manickam, S.; Muthurajan, R.

A Comparative Metabolomic

Analysis Reveals the Nutritional and

Therapeutic Potential of Grains of the

Traditional Rice Variety Mappillai

Samba. Plants 2022, 11, 543.

https: / / doi.org/10.3390/

plants11040543

Academic Editor: Jose Luis Perez

Received: 19 December 2021

Accepted: 26 January 2022

Published: 18 February 2022

Publisher's Note: MDPI stays neutral with regard to jurisdictional claims in published maps and institutional affiliations.

Copyright: (C) 2022 by the authors. Licensee MDPI, Basel, Switzerland. This article is an open access article distributed under the terms and conditions of the Creative Commons Attribution (CC BY) license (https:// creativecommons.org/licenses/by/ $4.0 /)$.

\author{
Department of Plant Biotechnology, Tamil Nadu Agricultural University, Coimbatore 641003, Tamil Nadu, India; \\ rajaranji@gmail.com (V.R.R.); sudhatamil@gmail.com (S.M.) \\ * Correspondence: raveendrantnau@gmail.com
}

\begin{abstract}
Rice (Oryza sativa L.) is the staple food of the majority of the population, particularly in Asia and Africa. Enriching rice with nutritional and therapeutic contents can improve its benefits for patients with lifestyle disorders. This study aimed to profile the phytochemical contents of the therapeutically known traditional rice Mappillai Samba against white rice CBMAS 14065 using nontargeted gas chromatography-mass spectrometry (GC-MS/MS). An analysis of the data using a mass spectrometry-data independent analysis (MS-DIAL) and MetaboAnalyst identified 113 metabolites belonging to 21 different classes of metabolites. A partial least square-discriminant analysis (PLS-DA) revealed 43 variable importance in projection (VIP) metabolites. This study identified therapeutically important metabolites, including phenylpropanoids, phytosterols, flavonoids, and polyamines, in the grains of Mappillai Samba. Three significant metabolic pathways, viz., phenylpropanoid biosynthesis, ubiquinone and other terpenoid-quinone biosynthesis, and steroid biosynthesis, were responsible for the grain metabolome variation between CBMAS 14065 and Mappillai Samba. Overall, the results of this study unravelled the biochemical complexity of Mappillai Samba, paving the way for the genetic mapping of the therapeutic compound accumulation in rice and the development of similar therapeutic rice varieties through molecular breeding.
\end{abstract}

Keywords: traditional rice; Mappillai Samba; metabolomics; therapeutic compounds; phytosterols; antioxidants

\section{Introduction}

Rice is one of the most important staple foods of nearly more than half of the global population, and the majority of Asians consume rice thrice a day. Rice production has increased by $>117 \%$ (from 257 million tons in the 1960s to 570 million tons in 2000) through the introduction of high yielding semi-dwarf varieties and hybrids [1]. Although rice is considered to be a high energy and high calorie cereal, its grains contain low amounts of protein, minerals, and nutrients [2]. Increased rice consumption is related to the prevalence of diabetes, which in turn leads to a susceptibility to neurological complications, cardiovascular diseases, retinopathy, foot ulcers, and renal diseases [3]. It has also been reported to aggravate the prevalence of anaemia in women. After the first green revolution, rice improvement programs were mainly aimed at increasing yields, with minimal attention paid toward improving the nutritional quality. The global population is predicted to reach 9.7 billion by 2050 [4], and achieving food and nutritional security for the growing population is becoming a challenge. Considering its widespread consumption, the development and dissemination of rice with nutritional and therapeutic values may have a significant impact on the general health and nutritional status of rural women and children where rice is the major source of daily calorie needs. 
High yielding rice varieties do not possess high contents of the nutritional and therapeutic phytochemicals that are abundant in traditional rice varieties and landraces. Several traditional rice genotypes have been reported to possess nutritional/therapeutic phytochemicals such as flavonoids, anthocyanins, $\gamma$-oryzanol, phytosterols, GABA, tocopherol, tricin, and carotenoids (lutein and beta-carotene), which attenuate the incidence of noncommunicable diseases (cardiovascular diseases, diabetes, retinopathy, cancer, and strokes) and help in maintaining the general health of pregnant women and children [5-8]. Traditional rice genotypes, viz., Njavara from Kerala [9,10] and Kavuni from Tamil Nadu [11], are known for their antidiabetic, anticancer, and other medicinal/therapeutic properties. The consumption of biofortified rice varieties with the nutritional and therapeutic values of traditional rice may help in managing health issues such as obesity, hypertension, diabetes, and oedemas $[12,13]$.

The development of biofortified rice varieties requires a thorough understanding of genetic variation in the accumulation of metabolites. Non-targeted metabolomics allows us to profile the majority of secondary metabolites in plants. An assessment of nutritional and bioactive phytochemicals through targeted LC-MS/MS in selected scented and pigmented rice varieties has revealed the presence of 4-hydroxy benzoic acid, apigenin, tricin, avenasterol, coumarin, coumaric acid, phenyl alanine, caffeic acid, and $\alpha$-tocophenol [14]. In this study, a non-targeted metabolomics approach was used to analyse the metabolomic profiles of a popular traditional rice variety, Mappillai Samba (Bridegroom's Rice) and a high yielding white rice genotype, type CBMAS 14065. Mappillai Samba (also known as Bridegroom's Rice), a red rice variety of Tamil Nadu, India, is known for its health benefits. Independent studies have reported its antihypercholesterolemic effect, anticancer activity, ability to improve fertility in men [15] as well as antidiabetic [16] and antineurological properties [17]. However, no systematic studies have been conducted to unravel the metabolome complexity of Mappillai Samba, which would allow us to map these traits and use them for breeding applications.

\section{Results}

\subsection{Characteristics of Mappillai Samba and CBMAS 14065}

Mappillai Samba is a long-duration rice genotype with bold, red grains whereas CBMAS 14065 is a medium-duration rice variety with white, medium-slender grains (Table 1; Figure 1).

Table 1. Details of the agronomic characteristics of rice genotypes CBMAS 14065 and Mappillai Samba.

\begin{tabular}{ccccc}
\hline Cultivar & Origin & Days to Maturity & Pedigree & Features \\
\hline Mappillai Samba & $\begin{array}{c}\text { Traditional variety, Tamil } \\
\text { Nadu, India }\end{array}$ & 155 to 160 days & Unknown & Brownish kernel \\
$\begin{array}{c}\text { CBMAS 14065 } \\
\text { (Pre-release cultivar) }\end{array}$ & TNAU, Coimbatore, India & 130 to 135 days & White Ponni x Apo & $\begin{array}{c}\text { Drought tolerant, high } \\
\text { yielding, fine quality, } \\
\text { white kernel }\end{array}$ \\
\hline
\end{tabular}




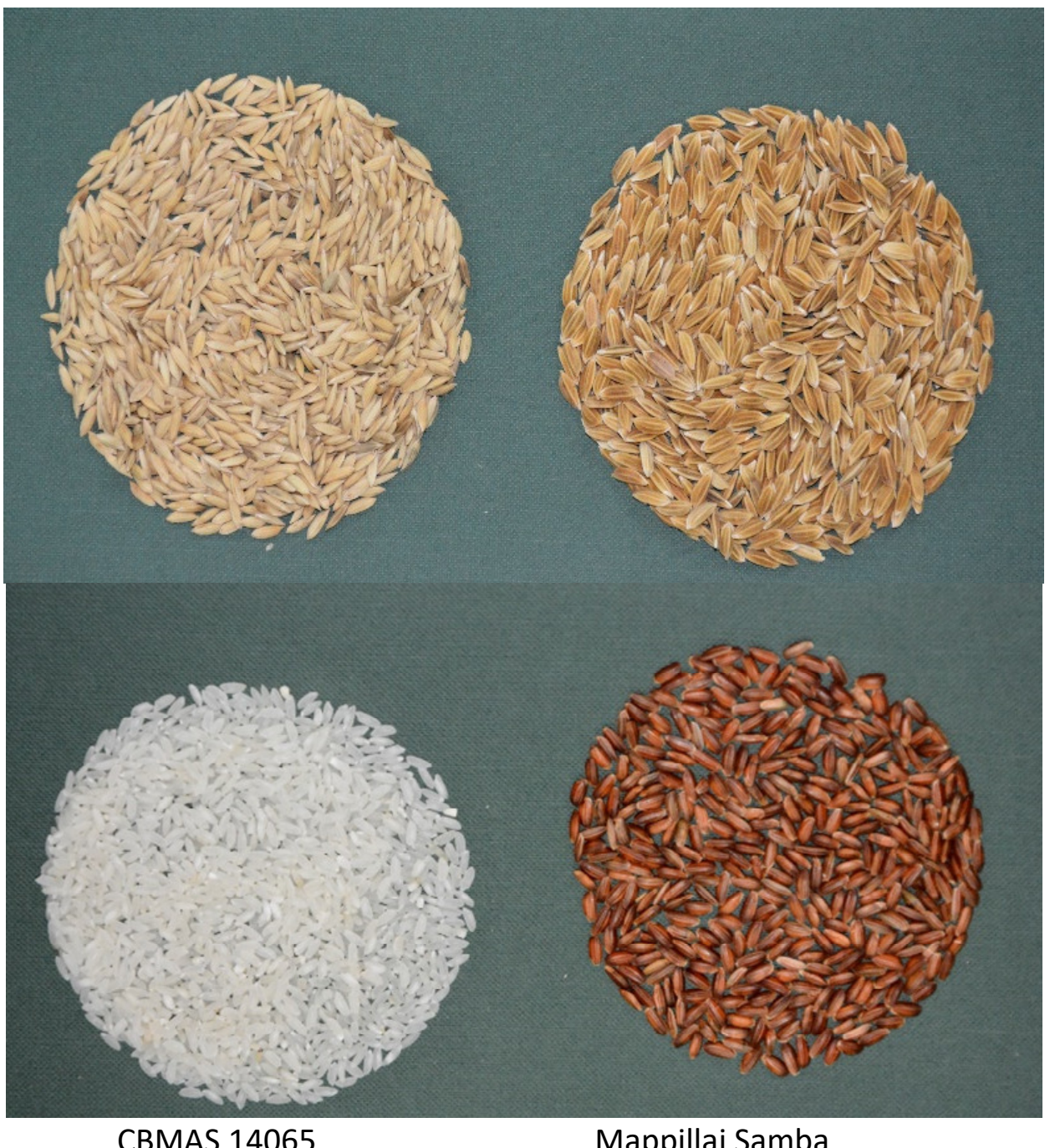

Figure 1. Grain characteristics of the rice genotypes CBMAS 14065 and Mappillai Samba.

\subsection{Metabolite Profiles of the Contrasting Rice Genotypes}

The metabolomic profiling of the grains of Mappillai Samba and CBMAS 14065 identified 113 known compounds (Supplementary Table S1 and Figure S1) belonging to 21 different metabolite classes, viz., carboxylic acids (29 compounds), amino acids (27 compounds), fatty acids (16 compounds), and phenylpropanoids (10 compounds) (Figure 2$)$. The mapping of these metabolites against 34 different sub-pathways listed in KEGG revealed that the majority of these metabolites are involved in phenylpropanoid biosynthesis (8); valine, leucine, and isoleucine biosynthesis (8); arginine and proline biosynthesis (7); and ubiquinone and other terpenoid-quinone biosynthesis (7) (Figure 3). 


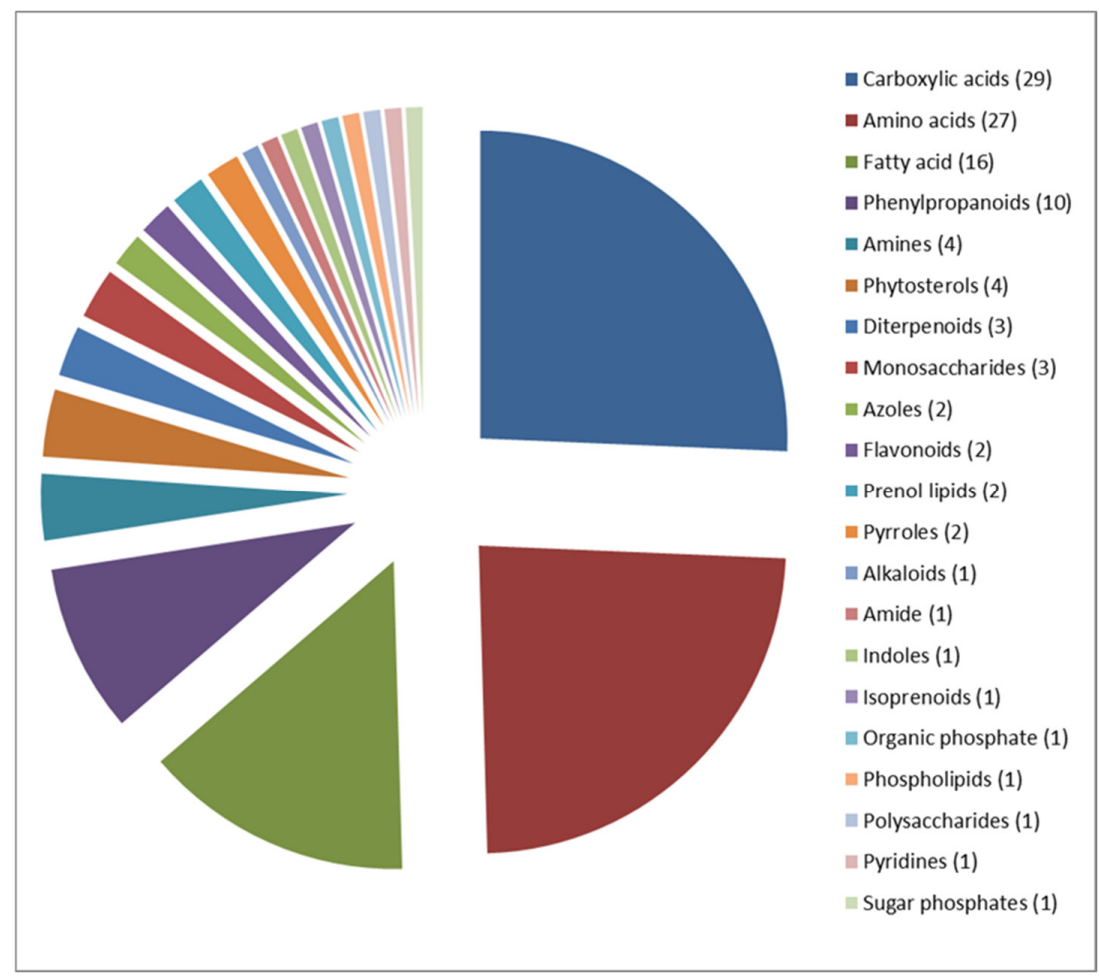

Figure 2. Classification of 113 metabolites identified in the grains of Mappillai Samba and CBMAS 14065 into 21 different metabolite classes. The number in parentheses indicates the number of metabolites mapped against each metabolite class.

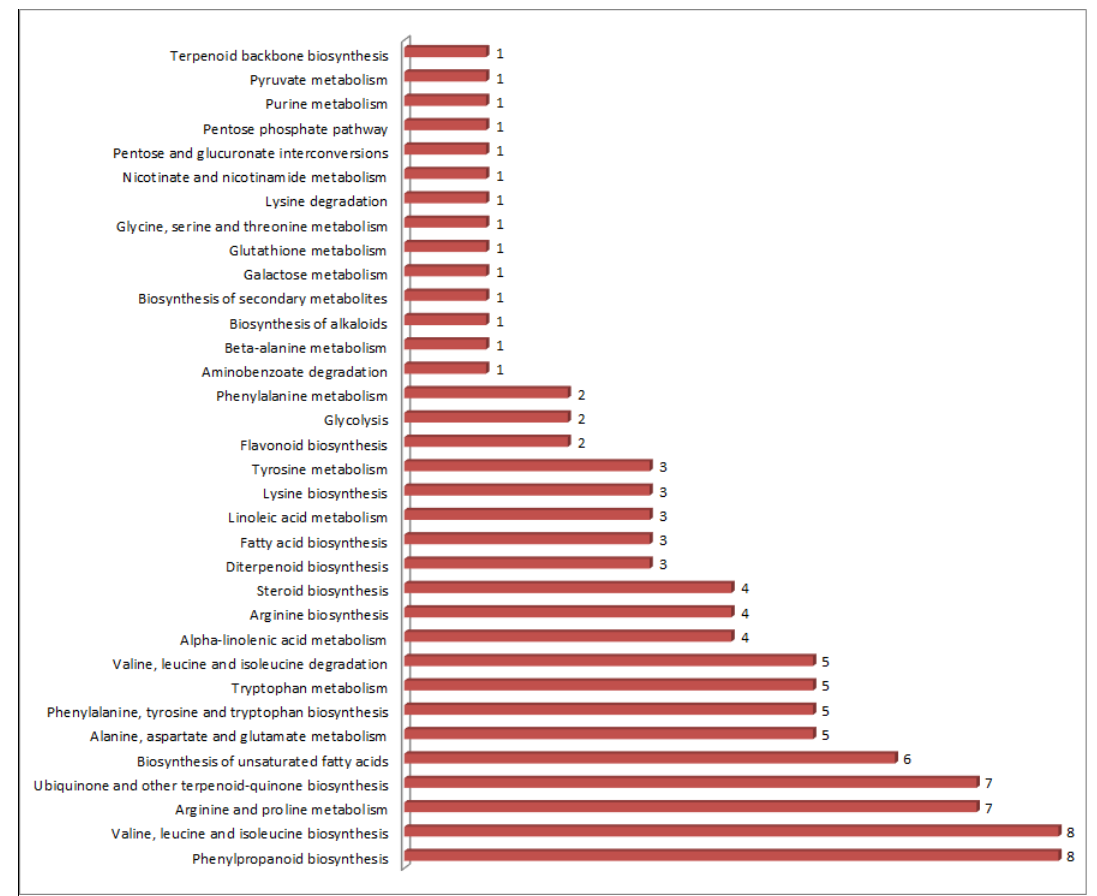

Figure 3. Mapping of 113 different metabolites belonging to 21 different classes against 34 subpathways listed in KEGG (Kyoto Encyclopaedia of Genes and Genomes). Values indicate the number of metabolites mapped against the respective pathway. 


\subsection{Univariate and Multivariate Analyses}

Hierarchical clustering based on the metabolite profiles of Mappillai Samba and CBMAS 14065 revealed distinct differences between the two genotypes. A principal component analysis (PCA) provided an initial estimate of the metabolic differences between the red grain Mappillai Samba and the white grain CBMAS 14065. The results of the PCA revealed that the first component PC1 explained $69.8 \%$ of the variance and PC2 explained $15.6 \%$ of the cumulative variance of $85.4 \%$ (Figure 4 ). The results of the partial least square-discriminant analysis (PLS-DA) also captured similar differences with a cumulative variance of $83.7 \%$ (component 1 explaining $69.3 \%$ and component 2 explaining $14.4 \%$ of the variance) (Figure 5).

Among the 113 metabolites annotated, the PLS-DA identified 43 VIP metabolites discriminating the grains of Mappillai Samba and CBMAS 14065 with a VIP score of $>1$ (Table 2; Figure 6). A heat map of the VIP metabolites revealed that the therapeutic metabolites phenylpropanoids, flavonoids, phytosterols, and amino acids were abundant in the grains of Mappillai Samba whereas stress-related amino acids and sugar compounds, including spermine, GABA, xylitol, gluconic acid, and glucopyranose, were abundant in the grains of CBMAS 14065 (Figure 6). A heat map analysis of all the identified 113 metabolites (Supplementary Figure S2) revealed that therapeutic metabolites were abundant in the grains of Mappillai Samba whereas stress-related amino acids and sugars were abundant in the grains of the white rice cultivar CBMAS 14065.

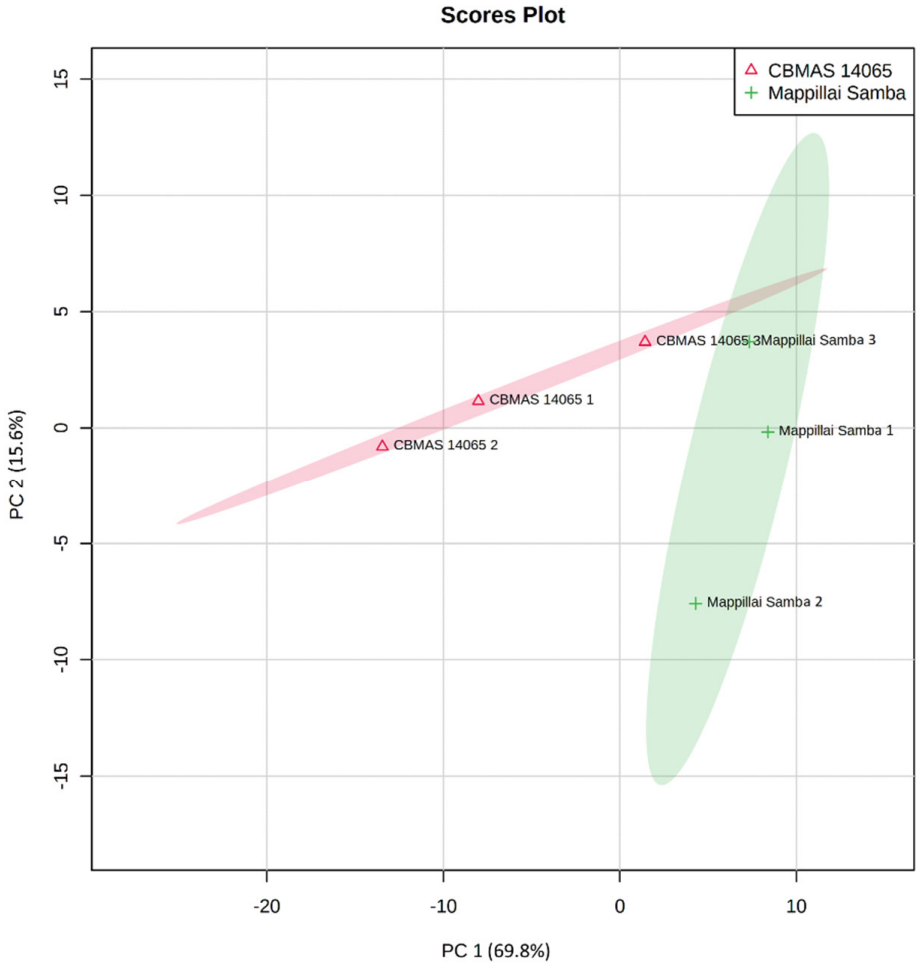

Figure 4. Principal component analysis showing the uniqueness of grain metabolomic profiles between Mappillai Samba and CBMAS 14065. PC1 explained a variation of $69.8 \%$ and PC2 explained a $15.6 \%$ variation (cumulative variance of $85.4 \%$ ). 


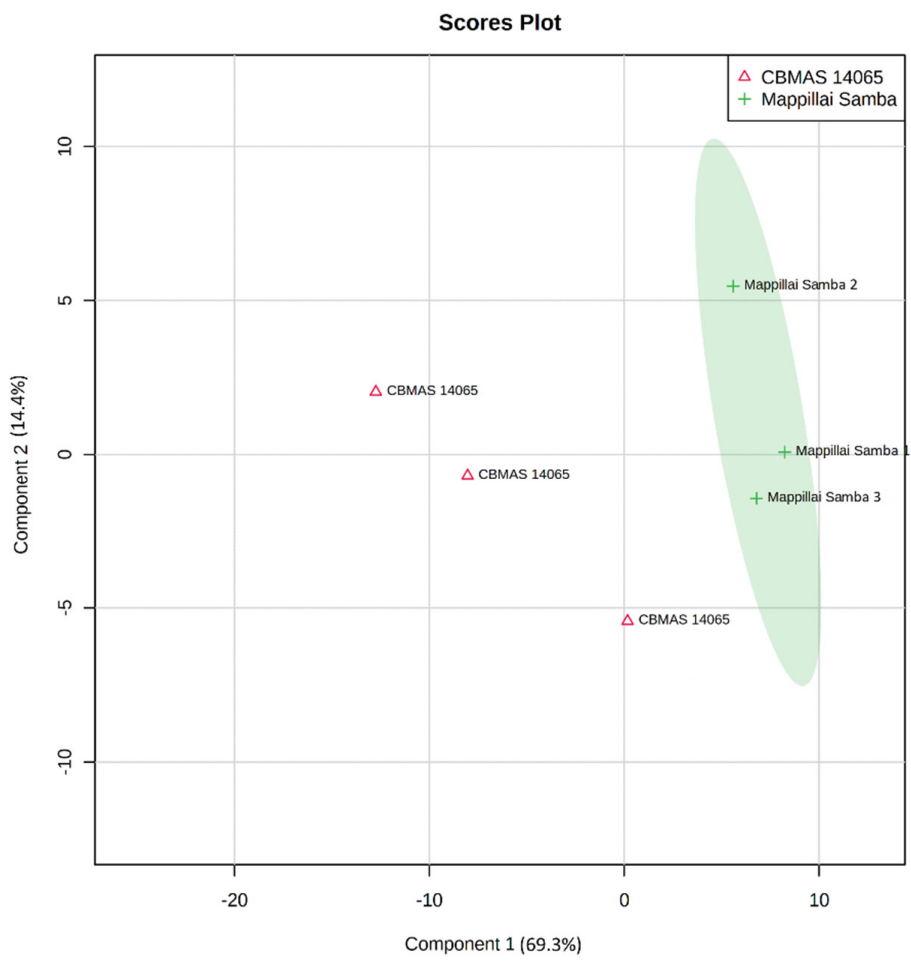

Figure 5. Partial least-square discriminant analysis discriminating Mappillai Samba and CBMAS 14065 based on the grain metabolome (cumulative variance of $83.7 \%$; $69.3 \%$ and $14.4 \%$ variance explained by components 1 and 2, respectively).

Table 2. List of the significant metabolites differentiating the grains of Mappillai Samba and CBMAS 14065 based on the VIP scores of the PLS-DA.

\begin{tabular}{|c|c|c|c|c|}
\hline S. No & Annotated Metabolite & Class & Pathway Involved & $\begin{array}{c}\text { PLS-DA } \\
\text { VIP }\end{array}$ \\
\hline 1 & Trans-4-Coumaric acid & Phenylpropanoid & $\begin{array}{l}\text { Ubiquinone and other terpenoid-quinone } \\
\text { biosynthesis }\end{array}$ & 1.8064 \\
\hline 2 & Alpha-tocopherol & Prenol lipid & $\begin{array}{l}\text { Ubiquinone and other terpenoid-quinone } \\
\text { biosynthesis }\end{array}$ & 1.7903 \\
\hline 3 & 4-Acetyl-2-phenyl-1-pyrolline & Pyrrole & NA & 1.7889 \\
\hline 4 & Farnesol & Isoprenoid & Terpenoid backbone biosynthesis & 1.7077 \\
\hline 5 & Squalene & Phytosterol & Steroid biosynthesis & 1.6961 \\
\hline 6 & Pelargonic acid & Fatty acid & Biosynthesis of unsaturated fatty acids & 1.6936 \\
\hline 7 & GABA & Amino acid & Alanine, aspartate, and glutamate metabolism & 1.6808 \\
\hline 8 & Stigmasterol & Phytosterol & Steroid biosynthesis & 1.6785 \\
\hline 9 & 7-Hydroxyflavone & Flavonoid & Flavonoid biosynthesis & 1.6394 \\
\hline 10 & Eicosenoic acid & Fatty acid & Biosynthesis of unsaturated fatty acids & 1.635 \\
\hline 11 & Gluconic acid & Monosaccharide & Pentose phosphate pathway & 1.6149 \\
\hline 12 & Xylitol & Monosaccharide & Pentose and glucuronate interconversions & 1.5368 \\
\hline 13 & Genistein & Flavonoid & Flavonoid biosynthesis & 1.4862 \\
\hline 14 & Campesterol & Phytosterol & Steroid biosynthesis & 1.4331 \\
\hline 15 & Chorismic acid & Carboxylic acid & $\begin{array}{l}\text { Ubiquinone and other terpenoid-quinone } \\
\text { biosynthesis }\end{array}$ & 1.3917 \\
\hline 16 & 3-Hydroxydecanoic acid & Fatty acid & Biosynthesis of unsaturated fatty acids & 1.3803 \\
\hline 17 & Isovaleric acid & Fatty acid & Biosynthesis of alkaloids & 1.3743 \\
\hline 18 & Glucopyranose & Monosaccharide & Glycolysis & 1.3333 \\
\hline 19 & Beta-Sitosterol & Phytosterol & Steroid biosynthesis & 1.2974 \\
\hline 20 & Isoleucine & Amino acid & Valine, leucine, and isoleucine degradation & 1.2964 \\
\hline 21 & (S)-Malate & Carboxylic acid & Pyruvate metabolism & 1.2921 \\
\hline 22 & L-Leucine & Amino acid & Valine, leucine, and isoleucine degradation & 1.2155 \\
\hline 23 & Spermine & Amino acid & Arginine and proline metabolism & 1.2111 \\
\hline
\end{tabular}


Table 2. Cont.

\begin{tabular}{|c|c|c|c|c|}
\hline S. No & Annotated Metabolite & Class & Pathway Involved & $\begin{array}{c}\text { PLS-DA } \\
\text { VIP }\end{array}$ \\
\hline 24 & 3,4-Dimethoxycinnamic acid & Carboxylic acid & NA & 1.2007 \\
\hline 25 & L-Pyroglutamic acid & Amino acid & Glutathione metabolism & 1.1812 \\
\hline 26 & 1,3-Phenylenediamine & Amine & NA & 1.1774 \\
\hline 27 & Heptadecanoic acid & Fatty acid & Biosynthesis of unsaturated fatty acids & 1.1717 \\
\hline 28 & p-Coumaric acid & Phenylpropanoid & $\begin{array}{l}\text { Ubiquinone and other terpenoid-quinone } \\
\text { biosynthesis }\end{array}$ & 1.167 \\
\hline 29 & 2-Coumarinate & Phenylpropanoid & Phenylpropanoid biosynthesis & 1.1267 \\
\hline 30 & 1-Cyclohexylpyrrolidin-2-one & Pyrrole & NA & 1.1239 \\
\hline 31 & 5-Dodecenoic acid & Fatty acid & Fatty acid biosynthesis & 1.1156 \\
\hline 32 & Sinapoyl malate & Phenylpropanoid & Phenylpropanoid biosynthesis & 1.1009 \\
\hline 33 & Sinapoyl aldehyde & Phenylpropanoid & Phenylpropanoid biosynthesis & 1.0935 \\
\hline 34 & 2-Linoleoyl-glycerol & Phospholipid & NA & 1.0922 \\
\hline 35 & Gamma-Linolenic acid & Fatty acid & Linoleic acid metabolism & 1.0876 \\
\hline 36 & Caffeic aldehyde & Phenylpropanoid & Phenylpropanoid biosynthesis & 1.071 \\
\hline 37 & p-Coumaraldehyde & Phenylpropanoid & Phenylpropanoid biosynthesis & 1.0704 \\
\hline 38 & Linoleic acid & Fatty acid & Linoleic acid metabolism & 1.0614 \\
\hline 39 & Caffeyl alcohol & Phenylpropanoid & Phenylpropanoid biosynthesis & 1.0568 \\
\hline 40 & Alpha-cyano-4-hydroxycinnamic acid & Carboxylic acid & $\begin{array}{l}\text { Ubiquinone and other terpenoid-quinone } \\
\text { biosynthesis }\end{array}$ & 1.0485 \\
\hline 41 & 5-Hydroxyconiferaldehyde & Phenylpropanoid & Phenylpropanoid biosynthesis & 1.0484 \\
\hline 42 & L-Valine & Amino acid & Valine, leucine, and isoleucine degradation & 1.0215 \\
\hline 43 & L-Alanine & Amino acid & Alanine, aspartate, and glutamate metabolism & 1.0203 \\
\hline
\end{tabular}

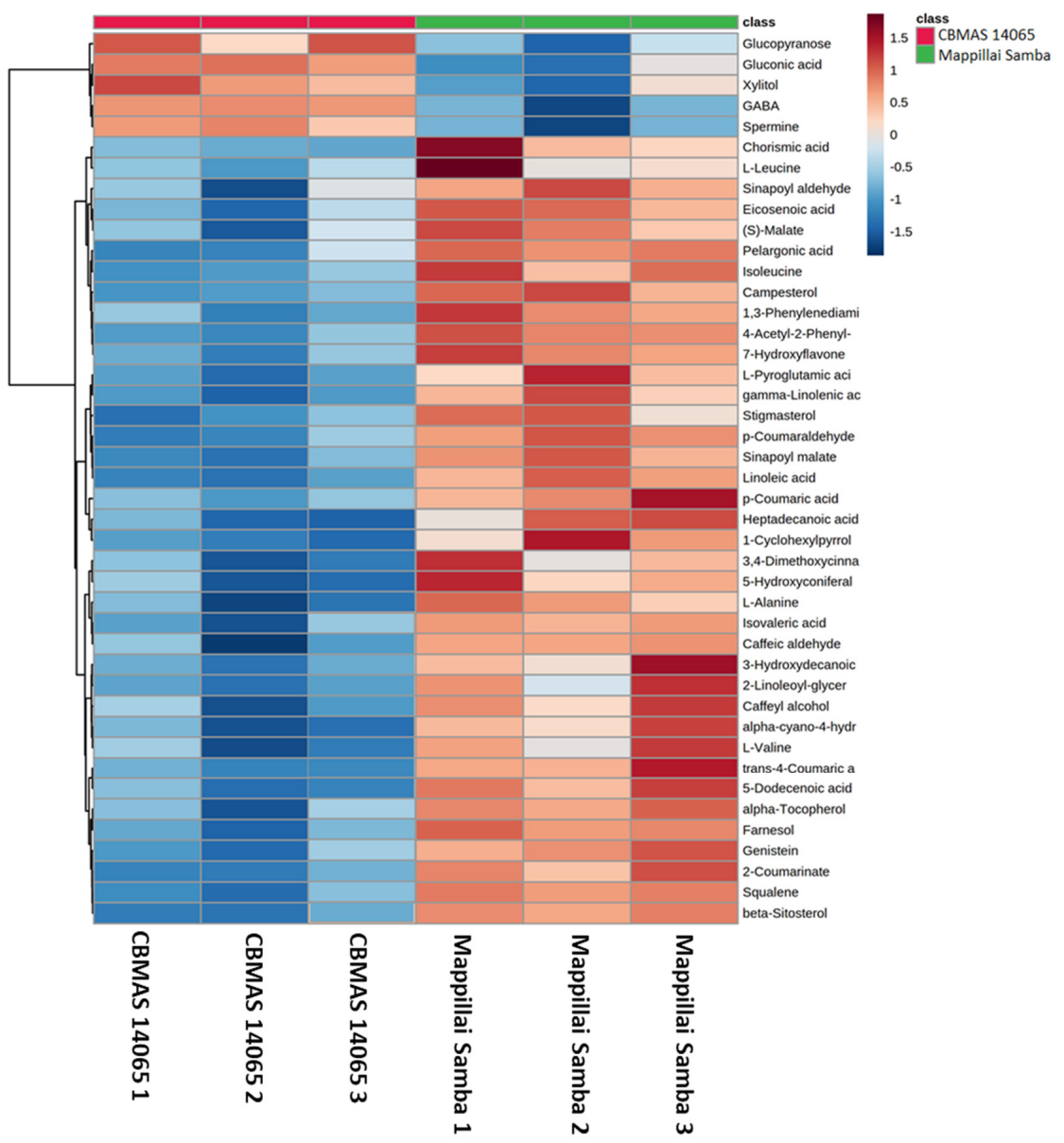

Figure 6. Heat map analysis showing the abundance of PLS-DA VIP metabolites between the grains of Mappillai Samba and CBMAS 14065. 


\subsection{Fold Change Analysis}

An estimation of the abundance ratio of 113 metabolites between the grains of Mappillai Samba and CBMAS 14065 revealed that 84 metabolites were upregulated and 8 metabolites were downregulated in the grains of Mappillai Samba (Supplementary Table S2). Most of the downregulated metabolites in the grains of Mappillai Samba were stress-related amino acids and sugars. The majority of the upregulated metabolites in the grains of Mappillai Samba were therapeutic metabolites, including phenylpropanoids, phytosterols, flavonoids, and amino acids.

\subsection{Pathway Analysis}

The pathway mapping of significant metabolites against the KEGG database identified three significant metabolic pathways with FDR values $\leq 0.05$. The phenylpropanoid pathway showed the highest $-\log (p)$ value of 3.2552 , followed by the ubiquinone and other terpenoid-quinone biosynthesis pathway (1.4771) and the steroid biosynthesis pathway (1.3282) (Table 3 and Figure 7).

Table 3. Major pathways discriminating the grain metabolome of Mappillai Samba and CBMAS 14065 .

\begin{tabular}{ccc}
\hline Pathway & Raw $p$ & $(-\log 10(p))$ \\
\hline Phenylpropanoid biosynthesis & 0.000556 & 3.2552 \\
Ubiquinone and other terpenoid-quinone biosynthesis & 0.033338 & 1.4771 \\
Steroid biosynthesis & 0.046969 & 1.3282 \\
\hline
\end{tabular}

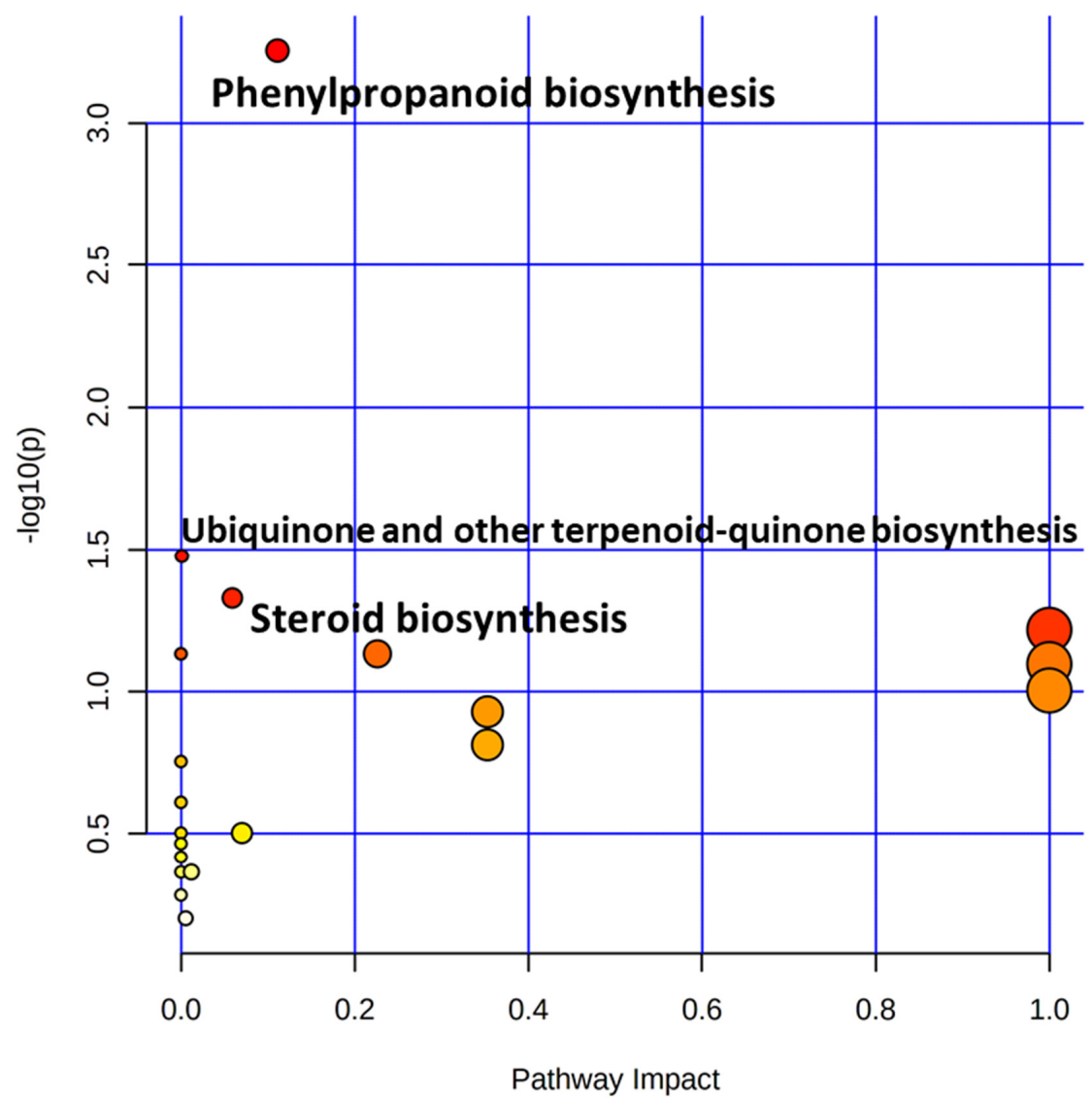

Figure 7. Metabolic pathways differentiating the grains of Mappillai Samba and CBMAS 14065. Each circle represents a metabolic pathway; the red circle indicates a higher impact and the yellow one indicates a lower impact. The size of the circle represents the number of differential metabolites present in the pathway. 


\section{Discussion}

Safeguarding the overall health status of humans requires an adequate intake of a nutritious and balanced diet. Fortifying a regular staple food crop such as rice with essential nutrients through genetic improvements can provide a sustainable solution. The development of rice with nutritional and therapeutic compounds could have a significant impact on the general health and nutritional status of the rural populations in India where rice remains the major source of daily calorie needs. The recently developed high yielding rice varieties do not possess the high nutritional content and therapeutic phytochemicals that are abundant in traditional rice varieties. A traditional rice genotype, Njavara of Kerala, has been reported to possess antidiabetic and anticancerous properties [9,10]. Similarly, a traditional rice genotype, Kavuni, was reported to possess therapeutic compounds that circumvented diabetes and age-related macular degeneration [11]. Similar other attempts have been made and rice varieties possessing anti-inflammatory, anticancer, and antioxidant properties have been reported $[15,18]$.

Advanced molecular methods have been developed to analyse the transcriptomes, proteomes, and metabolomes of crop plants [19]. Plant metabolomics through the targeted and non-targeted profiling of the metabolome has permitted a quality analysis [20,21], drug discovery [22], the detection of GM products [23], and the detection of biohazards [24]. A large-scale metabolomic study using GC-MS and UHPLC-MS/MS in a set of diverse rice genotypes (comprising both japonica and indica cultivars) identified 121 metabolites that significantly differentiated the two subspecies. Metabolomic data clearly indicated that the grains of indica rice contained increased levels of $\gamma$-tocopherol, $\gamma$-tocotrienol, and pyridoxate but reduced levels of phytic acid, gluconate, and nicotianamine compared with the grains of japonica [25]. In another study, a GC-MS/UHPLC-MS analysis of rice grains led to the identification of 214 metabolites [26]. A metabolomic analysis of the giant embryo rice Shangshida No. 5 revealed the presence of high levels of bioactive compounds such as GABA, arabinose, $\beta$-alanine, glutathione, VB6, xylitol, and xylose [27]. It was also demonstrated that indica and japonica rice considerably differed in their grain flavonoid composition, which was attributed to the sequence variations in the genes involved in flavonoid biosynthesis [28].

The present study aimed to unravel the grain metabolome complexity of the traditional rice variety Mappillai Samba, which is known for its nutritional and therapeutic properties. Mappillai means newlywed bridegroom and this rice (Mappillai Samba) is named after the reason that it is capable of improving the health and body power of Mappillai. A few studies have attempted to target the quantification of carbohydrates, proteins, and antioxidants in the grains of Mappillai Samba but there is no holistic study analysing its secondary metabolite composition [15-17]. In this study, the grain metabolites of Mappillai Samba and the white rice genotype CBMAS 14065 were profiled using GC-MS/MS.

A GC-MS/MS analysis of the grains of Mappillai Samba and CBMAS 14065 revealed a total of 113 metabolites (Supplementary Table S1) belonging to 21 different metabolite classes mapped onto 34 different KEGG pathways (Figure 3). Of these 113 metabolites, 43 were found to differentiate the grains of Mappillai Samba and CBMAS 14065 (Figure 6). The PCA results revealed a distinct separation of the two rice varieties based on their metabolite contents. A fold change analysis revealed that therapeutic metabolites such as phenylpropanoids, phytosterols, flavonoids, and amino acids were upregulated whereas stress-related amino acids and sugars were downregulated in the grains of Mappillai Samba, as reported earlier $[15,16,18]$.

The PLS-DA identified a total of 43 significant metabolites (VIP score $>1$ ) belonging to phenylpropanoids and phytosterols, which are known for their antihypercholesterolemic, anti-infertility, antioxidant, and anticancer properties [15,18]. Heat map and fold change analyses also confirmed the abundance of phenylpropanoids, steroids, and a few other therapeutic metabolites in the grains of Mappillai Samba compared with those in the grains of CBMAS 14065. Phytosterols such as $\beta$-sitosterol, stigmasterol, and campesterol—which are naturally found in vegetable oils, nuts, legumes, whole grains, and fruit-have cholesterol- 
lowering, antioxidant, and anticancer properties [29]. In this study, all three important phytosterols, viz., campesterol (92-fold increase), stigmasterol (33-fold increase), and $\beta$ sitosterol (8.5-fold increase) were found to be more abundant in the grains of Mappillai Samba than in those of CBMAS 14065. Campesterol (with antioxidant and hypocholesterolemic effects) [18], $\beta$-sitosterol (with hypocholesterolemic, antisterility, and anticancerous effects) [30], and stigmasterol (used as a precursor in the production of semi-synthetic progesterone [31] and vitamin D3) [32] are known for their valuable health-benefiting properties. Stigmasterol has also been reported to exhibit antihepatotoxic, anti-inflammatory, antioxidant, antiviral, anticancer, and antihypercholesterolemic effects [15,18]. Another pharmaceutically important terpenoid compound, squalene-which possesses antioxidant, anticancer, immunostimulant, and lipoxygenase inhibitor activities-was also found to be abundant (29-fold) in the grains of Mappillai Samba [33]. Furthermore, Mappillai Samba grains were found to contain elevated levels of gamma-tocotrienol (133-fold) and alpha-tocopherol (76-fold). To the best of our knowledge, this is the first time that gammatocotrienol and alpha-tocopherol have been reported in the grains of Mappillai Samba. These significant therapeutic compounds in the grains of Mappillai Samba (Table 4) may be targeted for genetic mapping to facilitate the introgression of these traits into other popular varieties. In plants, polyamines have been reported to play important roles in fundamental cellular processes such as growth, differentiation, morphogenesis, and host defence [34]. In the current study, major polyamines such as putrescine and spermine were detected in the grains of Mappillai Samba [35]. The pathway analysis predicted that the grain metabolomic variation between the two genotypes was greatly contributed to by the phenylpropanoid pathway $(-\log (p)=3.2552)$, followed by the pathways for ubiquinone and terpenoid-quinone biosynthesis $(-\log (p)=1.4771)$ and steroid biosynthesis $(-\log (p)=1.3282)$. Overall, the present study sheds light on metabolome complexity in the grains of the traditional rice, Mappillai Samba.

Table 4. List of significant nutraceutical and therapeutic metabolites in Mappillai Samba and their potential applications.

\begin{tabular}{|c|c|c|c|c|}
\hline S. No & Metabolite & Class & Uses & References \\
\hline 1 & $\beta$-Sitosterol & Phytosterol & $\begin{array}{c}\text { Prevention of cervical cancer; hypocholesterolemic and } \\
\text { anti-inflammatory effects }\end{array}$ & [36] \\
\hline 2 & Campesterol & Phytosterol & $\begin{array}{c}\text { Antioxidant, hypocholesterolemic, and anti-inflammatory } \\
\text { effects }\end{array}$ & {$[18,29]$} \\
\hline 3 & Stigmasterol & Phytosterol & $\begin{array}{l}\text { Anticancer and cholesterol-lowering ability; reduces the } \\
\text { risk of cardiovascular diseases; anti-inflammatory, } \\
\text { antioxidant, antiviral, estrogenic, and hypocholesterolemic } \\
\text { effects }\end{array}$ & {$[15,18]$} \\
\hline 4 & Squalene & Phytosterol & $\begin{array}{c}\text { Anticancer, antibacterial, immunostimulant, and } \\
\text { cholesterol-lowering ability }\end{array}$ & {$[15,18]$} \\
\hline 5 & Trans-4-Coumaric acid & Phenylpropanoid & Antioxidant effect & [37] \\
\hline 6 & p-Coumaric acid & Phenylpropanoid & Antioxidant and antimelanogenic effects & [38] \\
\hline 7 & Chorismic acid & Carboxylic acid & $\begin{array}{c}\text { Key branch-point intermediate for the production of } \\
\text { primary and secondary metabolites }\end{array}$ & [39] \\
\hline 8 & 7-Hydroxyflavone & Flavonoid & Antioxidant effect & [40] \\
\hline 9 & Genistein & Flavonoid & Antitumour effect & [41] \\
\hline 10 & Gamma-tocotrienol & Prenol lipid & $\begin{array}{l}\text { Potent anticancer agent; lowers cholesterol levels; } \\
\text { antiosteoporotic agent }\end{array}$ & [42-44] \\
\hline 11 & Alpha-tocopherol & Prenol lipid & $\begin{array}{l}\text { Anticancer and antidiabetic effects; anti-infertility, } \\
\text { antioxidant, and cardioprotective effects }\end{array}$ & [18] \\
\hline 12 & Spermine & Amino acid & ROS scavenging; protection from stress & [45] \\
\hline 13 & Putrescine & Amino acid & Antioxidant effect & [46] \\
\hline
\end{tabular}




\section{Materials and Methods}

\subsection{Seed Material}

A traditional red rice genotype (Mappillai Samba) and a high yielding white rice genotype (CBMAS 14065) were used. Both genotypes were raised during Rabi (2020) at the Department of Rice, Tamil Nadu Agricultural University, Coimbatore, India. Freshly harvested rice seeds were dried, manually dehusked, and used for the GC-MS/MS analysis.

\subsection{Metabolite Extraction and Mass Spectrometric Analysis}

The secondary metabolites were extracted from the grains of CBMAS 14065 and Mappillai Samba using the Soxhlet extraction procedure as described previously [47]. The dehusked seeds of Mappillai Samba and CBMAS 14065 were pulverised using liquid nitrogen in a mortar and pestle. Approximately $25 \mathrm{mg}$ of the powdered rice sample was soaked in $100 \%$ methanol (HPLC grade) overnight. The mixture was kept in a water bath at $70{ }^{\circ} \mathrm{C}$ for $10 \mathrm{~min}$, followed by centrifugation at $13,000 \times \mathrm{g}$ for $10 \mathrm{~min}$ at $4{ }^{\circ} \mathrm{C}$. The supernatant was collected and filtered through a 0.2 micron filter. The filtered extracts were concentrated using a vacuum evaporator and vials containing $1 \mathrm{~mL}$ of the concentrated filtrate were fed into the mass spectrometer. A GC-MS/MS (Perkin Elmer Inc., Akron, OH, USA) instrument coupled with a DB-5 MS capillary standard non-polar column (30 Mts, ID: 0.25 mm, film: 0.25 IM, (Perkin Elmer Inc, Akron, OH, USA)), available at the Department of Agricultural Microbiology, Tamil Nadu Agricultural University, Coimbatore, India, was used. One microlitre of the methanolic extract of the sample was injected into the GC-MS/MS system with helium as the carrier gas. The peaks were detected for $30 \mathrm{~min}$. Toward the end of each run, an extremely high temperature $\left(260{ }^{\circ} \mathrm{C}\right)$ was maintained for approximately $5 \mathrm{~min}$, followed by washing the syringe (thrice) with the solvent (methanol) and equilibration (2-3 $\mathrm{min}$ ) to ensure the avoidance of contamination. The GC-MS/MS analysis was performed with a mass range scan of $50-1000 \mathrm{~m} / \mathrm{z} ; 70 \mathrm{eV}$ was applied for the fragmentation and the precursor ions were isolated with an isolation window of $10 \mathrm{~m} / \mathrm{z}$. The obtained raw mass spectra were converted to an $\mathrm{ABF}$ format using an ABF converter (www.reifycs.com/AbfConverter, 25 November 2021) for a further analysis.

\subsection{Statistical Analysis and Pathway Mapping}

The spectral peak processing and annotation were performed using MS-DIAL [48] as described previously [47]. The PCA and PLS-DA analyses were performed using MetaboAnalyst 5.0 (https:/ / www.metaboanalyst.ca/, 29 November 2021) [49] with the missing values being replaced by $1 / 5$ of the minimum positive values. The significant metabolites that discriminated Mappillai Samba and CBMAS 14065 were mapped onto metabolic pathways using MetaboAnalyst 5.0 [50]. The significant pathways that differed between Mappillai Samba and CBMAS 14065 were identified using the Kyoto Encyclopedia of Genes and Genomes (KEGG) database [51].

\section{Conclusions}

The present study aimed to generate the metabolic signatures of the traditional rice Mappillai Samba, which is known for its therapeutic value and health benefits. A GCMS/MS analysis identified 113 metabolites belonging to 21 different metabolite classes. PCA and PLS-DA analyses identified 43 unique metabolites that differentiated the grains of the two cultivars Mappillai Samba and CBMAS 14065. Pathway mapping revealed three significant pathways, viz., the phenylpropanoid biosynthesis pathway, the pathway for ubiquinone and other terpenoid-quinone biosynthesis, and the steroid biosynthesis pathway, contributing to the grain metabolome variation between Mappillai Samba and CBMAS 14065. A fold change analysis revealed that metabolites of nutraceutical and therapeutic importance-namely, phytosterols, squalene, and tocopherol-were more abundant in the grains of Mappillai Samba than in those of CBMAS 14065. Improving the traditional rice genotypes for yield and agronomic traits or improving the high yielding varieties for phytochemical contents may be potential strategies for the biofortification of staple 
food crops such as rice to circumvent major lifestyle disorders. The identified therapeutic/nutraceutical compounds in the grains of Mappillai Samba may serve as potential leads for genetic mapping of these pharmaceutically important traits, which will accelerate the development of high yielding rice varieties enriched with nutritional/therapeutic traits.

Supplementary Materials: The following are available online at https: / www.mdpi.com/article / 10.3390/plants11040543/s1, Figure S1: Chromatograms of Mappillai Samba and CBMAS 14065S; Figure S2: Heat map analysis of 113 metabolites in Mappillai Samba and CBMAS 14065; Table S1: List of metabolites identified in Mappillai Samba and CBMAS 14065; Table S2: The abundance ratio of 92 metabolites showed more than a 2-fold change between Mappillai Samba and CBMAS 14065.

Author Contributions: Conceptualisation, supervision, project administration, funding acquisition, and writing-review and editing, R.M.; methodology, formal analysis, resources, and writingoriginal draft preparation, V.R.R. and S.M. All authors have read and agreed to the published version of the manuscript.

Funding: This research received no external funding.

Data Availability Statement: Data are contained within this article and the Supplementary Information.

Acknowledgments: The authors are grateful to Sanjeev (GC-MS analysis), Ajay P. (data analysis), Rohit K. (sampling), and Bharathi A. (sample preparation) for their help.

Conflicts of Interest: The authors declare that there are no conflicts of interest.

\section{References}

1. Khush, G.S. Strategies for increasing yield potential in rice. Stud. Plant Sci. 2000, 7, 207-212.

2. Das, P.; Sanghamitra, A.; Majumdar, A.L. Genetic Manipulation for Improved Nutritional Quality in Rice. Front. Genet. 2020, 11, 1-19. [CrossRef] [PubMed]

3. Ramachandran, A.; Snehalatha, C.; Kapur, A.; Vijay, V.; Mohan, V.; Das, A.; Rao, P.; Yajnik, C.; Kumar, K.P.; Nair, J.D.; et al. High prevalence of diabetes and impaired glucose tolerance in India: National Urban Diabetes Survey. Diabetologia 2001, 44, $1094-1101$. [CrossRef] [PubMed]

4. United Nations. United Nations Report of Economic and Social Affairs; United Nations: New York, NY, USA, 2016.

5. Nagaraju, J.; Kathirvel, M.; Kumar, R.R.; Siddiq, E.; Hasnain, S.E. Genetic analysis of traditional and evolved Basmati and non-Basmati rice varieties by using fluorescence-based ISSR-PCR and SSR markers. Proc. Natl. Acad. Sci. USA 2002, 99, 5836-5841. [CrossRef] [PubMed]

6. Deepa, G.; Singh, V.; Naidu, K.A. Nutrient composition and physicochemical properties of Indian medicinal rice-Njavara. Food Chem. 2008, 106, 165-171. [CrossRef]

7. Yadav, K.S.; Naseeruddin, S.; Prashanthi, G.S.; Sateesh, L.; Rao, L.V. Bioethanol fermentation of concentrated rice straw hydrolysate using co-culture of Saccharomyces cerevisiae and Pichia stipitis. Bioresour. Technol. 2011, 102, 6473-6478. [CrossRef] [PubMed]

8. Imam, M.U.; Ismail, M. Nutrigenomic effects of germinated brown rice and its bioactives on hepatic gluconeogenic genes in type 2 diabetic rats and HEPG 2 cells. Mol. Nutr. Food Res. 2013, 57, 401-411. [CrossRef] [PubMed]

9. Smitha, M.; Jayalekshmy, A. Phytochemical Investigations on ‘Black Glumed' Njavara (Oryza sativa L.), the Medicinal Rice, as Compared to Staple Varieties and Evaluation of Their Antioxidant, Anti-Inflammatory and Anticancer Effects. Ph.D. Thesis, National Institute for Interdisciplinary Science and Technology (CSIR), Kerala, India, 2011.

10. Varghese, G.; Jose, M.; Dinesh Raj, R.; Bocianowski, J.; Thomas, G.; Omanakumari, N. Quantitative and molecular analyses reveal a deep genetic divergence between the ancient medicinal rice (Oryza sativa) Njavara and syntopic traditional cultivars. Ann. Appl. Biol. 2014, 164, 95-106. [CrossRef]

11. Valarmathi, R.; Raveendran, M.; Robin, S.; Senthil, N. Unraveling the nutritional and therapeutic properties of 'Kavuni' a traditional rice variety of Tamil Nadu. J. Plant Biochem. Biotechnol. 2015, 24, 305-315. [CrossRef]

12. Ahuja, U.; Ahuja, S.; Thakrar, R.; Singh, R. Rice-A nutraceutical. Asian Agri-Hist. 2008, 12, 93-108.

13. Das, A.; Kesari, V.; Rangan, L. Aromatic joha rice of Assam-A review. Agric. Rev. 2010, 31, 1-10.

14. Choudhury, P.; Dutta, K.N.; Singh, A.; Malakar, D.; Pillai, M.; Talukdar, N.C.; Samanta, S.K.; Devi, R. Assessment of nutritional value and quantitative analysis of bioactive phytochemicals through targeted LC-MS/MS method in selected scented and pigmented rice varietals. J. Food Sci. 2020, 85, 1781-1792. [CrossRef] [PubMed]

15. Priya, T.R.; Nelson, A.R.L.E.; Ravichandran, K.; Antony, U. Nutritional and functional properties of coloured rice varieties of South India: A review. J. Ethn. Foods 2019, 6, 11. [CrossRef]

16. Muralikrishnan, L.; Padaria, R.N.; Dass, A.; Choudhary, A.K.; Kakade, B.; Shokralla, S.; El-Abedin, T.K.Z.; Almutairi, K.F.; Elansary, H.O. Elucidating Traditional Rice Varieties for Consilient Biotic and Abiotic Stress Management under Changing Climate with Landscape-Level Rice Biodiversity. Land 2021, 10, 1058. [CrossRef] 
17. Arumugasamy, S.; Jayashankar, N.; Subramanian, K.; Sridhar, S.; Vijayalakshmi, K. Indigenous Rice Varieties; Centre for Indian Knowledge Systems (CIKS): Chennai, India, 2001; Volume 74.

18. Krishnanunni, K.; Senthilvel, P.; Ramaiah, S.; Anbarasu, A. Study of chemical composition and volatile compounds along with in-vitro assay of antioxidant activity of two medicinal rice varieties: Karungkuravai and Mappilai samba. J. Food Sci. Technol. 2015, 52, 2572-2584. [CrossRef] [PubMed]

19. Singh, R.K.; Sood, P.; Prasad, A.; Prasad, M. Advances in omics technology for improving crop yield and stress resilience. Plant Breed. 2021, 140, 719-731. [CrossRef]

20. Kusano, M.; Saito, K. Role of metabolomics in crop improvement. J. Plant Biochem. Biotechnol. 2012, 21, 24-31. [CrossRef]

21. Razzaq, A.; Sadia, B.; Raza, A.; Khalid Hameed, M.; Saleem, F. Metabolomics: A way forward for crop improvement. Metabolites 2019, 9, 303. [CrossRef] [PubMed]

22. Mukherjee, P.K. Plant metabolomics and quality evaluation of herbal drugs. In Quality Control and Evaluation of Herbal DrugsEvaluating Natural Products and Traditional Medicine; Mukherjee, P.K., Ed.; Elsevier: Amsterdam, The Netherlands, 2019; pp. 629-653.

23. Corujo, M.; Pla, M.; van Dijk, J.; Voorhuijzen, M.; Staats, M.; Slot, M.; Lommen, A.; Barros, E.; Nadal, A.; Puigdomènech, P.; et al. Use of omics analytical methods in the study of genetically modified maize varieties tested in 90 days feeding trials. Food Chem. 2019, 292, 359-371. [CrossRef] [PubMed]

24. Stewart, D.; Shepherd, L. Metabolomics for the safety assessment of genetically modified (GM) crops. In Metabolomics in Food and Nutrition; Elsevier: Amsterdam, The Netherlands, 2013; pp. 192-216.

25. Hu, C.; Shi, J.; Quan, S.; Cui, B.; Kleessen, S.; Nikoloski, Z.; Tohge, T.; Alexander, D.; Guo, L.; Lin, H.; et al. Metabolic variation between japonica and indica rice cultivars as revealed by non-targeted metabolomics. Sci. Rep. 2014, 4, 5067. [CrossRef]

26. Hu, C.; Tohge, T.; Chan, S.-A.; Song, Y.; Rao, J.; Cui, B.; Lin, H.; Wang, L.; Fernie, A.R.; Zhang, D.; et al. Identification of conserved and diverse metabolic shifts during rice grain development. Sci. Rep. 2016, 6, 20942. [CrossRef]

27. Zhao, G.-C.; Zhang, Y.-X.; Sun, S.-Y.; Xie, M.-X.; Hu, C.-Y.; Shi, Y.-Q.; Shi, J.-X.; Li, J.-Y. Identification of the biochemical characteristics of developing giant embryo rice grains using non-targeted metabolomics. J. Cereal Sci. 2019, 85, 70-76. [CrossRef]

28. Dong, X.; Chen, W.; Wang, W.; Zhang, H.; Liu, X.; Luo, J. Comprehensive profiling and natural variation of flavonoids in rice. J. Integr. Plant Biol. 2014, 56, 876-886. [CrossRef] [PubMed]

29. Vezza, T.; Canet, F.; de Marañón, A.M.; Bañuls, C.; Rocha, M.; Víctor, V.M. Phytosterols: Nutritional Health Players in the Management of Obesity and Its Related Disorders. Antioxidants 2020, 9, 1266. [CrossRef] [PubMed]

30. Gupta, R.; Sharma, A.K.; Dobhal, M.; Sharma, M.; Gupta, R. Antidiabetic and antioxidant potential of $\beta$-sitosterol in streptozotocininduced experimental hyperglycemia. J. Diabetes 2011, 3, 29-37. [CrossRef] [PubMed]

31. Sundararaman, P.; Djerassi, C. A convenient synthesis of progesterone from stigmasterol. J. Org. Chem. 1977, 42, 3633-3634. [CrossRef]

32. Kametani, T.; Furuyama, H. Synthesis of vitamin D3 and related compounds. Med. Res. Rev. 1987, 7, 147-171. [CrossRef]

33. Lozano-Grande, M.A.; Gorinstein, S.; Espitia-Rangel, E.; Dávila-Ortiz, G.; Martínez-Ayala, A.L. Plant sources, extraction methods, and uses of squalene. Int. J. Agron. 2018, 2018, 1829160. [CrossRef]

34. Walters, D. Resistance to plant pathogens: Possible roles for free polyamines and polyamine catabolism. New Phytol. 2003, 159, 109-115. [CrossRef] [PubMed]

35. Moselhy, S.S.; Asami, T.; Abualnaja, K.O.; Al-Malki, A.L.; Yamano, H.; Akiyama, T.; Wada, R.; Yamagishi, T.; Hikosaka, M.; Iwakawa, J.; et al. Spermidine, a polyamine, confers resistance to rice blast. J. Pestic. Sci. 2016, 41, 79-82. [CrossRef] [PubMed]

36. Saeidnia, S.; Manayi, A.; Gohari, A.R.; Abdollahi, M. The story of beta-sitosterol-A review. Eur. J. Med. Plants 2014, 4, 590-609. [CrossRef]

37. Alicja, U.; Marcin, M.; Małgorzata, S. Quantum-Chemical calculations of the antioxidant properties of trans-p-coumaric acid and trans-sinapinic acid. CMST 2012, 18, 117-128.

38. Boo, Y.C. p-Coumaric acid as an active ingredient in cosmetics: A review focusing on its antimelanogenic effects. Antioxidants 2019, 8, 275. [CrossRef]

39. Wood, H.B.; Ganem, B. Short chemical synthesis of (-)-chorismic acid from (-)-shikimic acid. J. Am. Chem. Soc. 1990, 112, 8907-8909. [CrossRef]

40. Sengupta, B.; Sahihi, M.; Dehkhodaei, M.; Kelly, D.; Arany, I. Differential roles of 3-Hydroxyflavone and 7-Hydroxyflavone against nicotine-induced oxidative stress in rat renal proximal tubule cells. PLoS ONE 2017, 12, e0179777. [CrossRef]

41. Thangavel, P.; Puga-Olguín, A.; Rodríguez-Landa, J.F.; Zepeda, R.C. Genistein as potential therapeutic candidate for menopausal symptoms and other related diseases. Molecules 2019, 24, 3892. [CrossRef]

42. Ghosh, S.P.; Kulkarni, S.; Hieber, K.; Toles, R.; Romanyukha, L.; Kao, T.-C.; Hauer-Jensen, M.; Kumar, K.S. Gamma-Tocotrienol, a tocol antioxidant as a potent radioprotector. Int. J. Radiat. Biol. 2009, 85, 598-606. [CrossRef] [PubMed]

43. Ling, M.T.; Luk, S.U.; Al-Ejeh, F.; Khanna, K.K. Tocotrienol as a potential anticancer agent. Carcinogenesis 2012, 33, 233-239. [CrossRef]

44. Xu, W.; He, P.; He, S.; Cui, P.; Mi, Y.; Yang, Y.; Li, Y.; Zhou, S. Gamma-tocotrienol stimulates the proliferation, differentiation, and mineralization in osteoblastic MC3T3-E1 cells. J. Chem. 2018, 2018, 3805932. [CrossRef]

45. Pegg, A.E. The function of spermine. IUBMB Life 2014, 66, 8-18. [CrossRef] [PubMed] 
46. Matkovics, B.; Kecskemeti, V.; Varga, S.I.; Novak, Z.; Kertesz, Z. Antioxidant properties of di-and polyamines. Comp. Biochem. Physiology. B Comp. Biochem. 1993, 104, 475-479. [CrossRef]

47. Ramalingam, A.P.; Mohanavel, W.; Premnath, A.; Muthurajan, R.; Prasad, P.; Perumal, R. Large-Scale Non-Targeted Metabolomics Reveals Antioxidant, Nutraceutical and Therapeutic Potentials of Sorghum. Antioxidants 2021, 10, 1511. [CrossRef] [PubMed]

48. Tsugawa, H.; Cajka, T.; Kind, T.; Ma, Y.; Higgins, B.; Ikeda, K.; Kanazawa, M.; VanderGheynst, J.; Fiehn, O.; Arita, M. MS-DIAL: Data-independent MS/MS deconvolution for comprehensive metabolome analysis. Nat. Methods 2015, 12, 523-526. [CrossRef] [PubMed]

49. Pang, Z.; Chong, J.; Zhou, G.; de Lima Morais, D.A.; Chang, L.; Barrette, M.; Gauthier, C.; Jacques, P.-É.; Li, S.; Xia, J. MetaboAnalyst 5.0: Narrowing the gap between raw spectra and functional insights. Nucleic Acids Res. 2021, 49, W388-W396. [CrossRef]

50. Xia, J.; Wishart, D.S. MetPA: A web-based metabolomics tool for pathway analysis and visualization. Bioinformatics 2010, 26, 2342-2344. [CrossRef]

51. Li, S.; Park, Y.; Duraisingham, S.; Strobel, F.H.; Khan, N.; Soltow, Q.A.; Jones, D.P.; Pulendran, B. Predicting network activity from high throughput metabolomics. PLoS Comput. Biol. 2013, 9, e1003123. [CrossRef] 